\title{
REVISÃO INTEGRATIVA DA LITERATURA: O BRINCAR LIVRE NA EDUCAÇÃO INFANTIL
}

\author{
Marco Aurélio Gonçalves Nóbrega dos Santos ${ }^{1}$ \\ Elisabeth Ângela Mamede Correa ${ }^{2}$
}

RESUMO: Esta pesquisa visa analisar a produção de conhecimento acerca do tema "Brincar Livre" na educação infantil dentro das instituições escolares. Trata-se de uma revisão integrativa da literatura, na qual se utilizou critérios de seleção, artigos indexados na base de dados SciElo, entre os anos de 20II a 2020. O objetivo do presente estudo foi sistematizar pesquisas já realizadas sobre a contribuição do brincar livre na busca da compreensão da dimensão pedagógica do brincar livre, seus espaços e ampliar as reflexões acerca do papel das instituições e do professor como mediador nesse processo. A amostra foi constituída por o8(oito) artigos, nos quais os resultados revelaram a necessidade de maiores articulações nos processos pedagógicos nas instituições que possibilitem melhor compreensão sobre a importância do brincar livre no processo de ensino aprendizagem e consequentemente na melhor qualidade de ensino na educação infantil.

Palavras-chave: Brincar. Brincar Livre. Educação Infantil.

ABSTRACT: This research aims to analyze the production of knowledge about the theme "Free Play" in early childhood education within school institutions. This is an integrative literature review, in which selection criteria were used, articles indexed in the SciElo database, from 2011 to 2020. The objective of this study was to systematize research already carried out on the contribution of free play in the search to understand the pedagogical dimension of free play, its spaces and expand reflections on the role of institutions and the teacher as a mediator in this process. The sample consisted of o8 (eight) articles, in which the results revealed the need for greater articulation in the pedagogical processes in institutions that enable a better understanding of the importance of free play in the teaching-learning process and, consequently, in the best quality of teaching in education childish.

Keywords: Play. Play Free. Child education.

${ }_{2}^{\mathrm{I}}$ marcoaurelio67@hotmail.com. 


\section{INTRODUÇÃO}

O brincar representa uma importante ferramenta quando se trata de assuntos relacionados ao desenvolvimento cognitivo, afetivo e psicomotor das crianças. No brincar é que a criança desenvolve novas experiências de vida, não existindo um formato ou um padrão que imponha limites a sua imaginação. A criança é um ser em desenvolvimento, que se comunica, vive e interage no mundo com maneiras e formas originais. Se identifica através da imaginação, do movimento, do afeto, do prazer, da imaginação e da brincadeira. Segundo Kishimoto (2oro, p. I), “[...] o brincar é uma ação livre, que surge a qualquer hora, iniciada e conduzida pela criança. [...] a opção pelo brincar desde o início da educação infantil é o que garante a cidadania da criança e ações pedagógicas de maior qualidade”.

A denominação brincar livre é uma atividade lúdica, livre de regras, imposições, estímulos intencionais e objetivos de aprendizagem. A criança tem a oportunidade de explorar sua criatividade dentro do seu próprio tempo, criar regras em suas brincadeiras e vínculos de amizade com outras crianças sem a intervenção de um adulto, de forma a melhor se integrar com o meio e no meio em que está inserida (GARIÉPY; HOWE, 2003; ALVES; BIANCHI, 2010; PENINA, 2016).

O brincar livre oportuniza à criança autonomia para que interaja com o meio que faz parte já que é um momento enriquecedor de possibilidades, além disso é nesse momento do brincar livre que o professor se aproxima mais e conhece as peculiaridades, particularidades e especificidades de seus alunos, o que the proporciona não só conhecer o que as crianças gostam de brincar, mas principalmente ampliar, desafiar, propor, estimular e sobretudo favorecer a aprendizagem de forma significativa com a construção da autonomia e liberdade (SMITH, 2006). 
Bispo, Dourado e Dourado (2019) defendem que currículos devem ser constituídos com a cultura lúdica, do brincar livre e que possam aproximar de uma educação infantil com e para as crianças, nas quais possam tomar decisões e escolher o brincar que proporcione liberdade e autonomia. Porém, para que o brincar livre aconteça com qualidade o papel do professor é fundamental, não bastando planejar e organizar espaços, mas principal ter um papel sensível de mediador.

A importância de compreender o brincar na educação infantil, surgiu a partir do momento em que a infância passou a ter diferentes significados perante a sociedade. Estes valores representam o retrato da infância em diversos contextos no decorrer de séculos, desde a época em que a criança era considerada como um mini adulto até o momento em que começou a exercer seu papel como um ser histórico marcado pelo momento real da humanidade. Com este marco histórico, chegou-se ao c onsenso da notoriedade da criança na infância e da reflexão do brincar durante esse período (ARIÈS, I98I).

Podemos afirmar que a criança se encontra inserida em uma cultura de imobilização, pela qual deve se comportar e obedecer a regras estabelecidas por adultos, que interpretam o brincar como sinônimo de bagunça. A infância vai perdendo gradativamente sua importância; fazendo com que a criança deixe de ser espontânea, criativa, ousada, sensível; abstendo de sua capacidade de multiplicar linguagens expressas em gestos e movimentos. Devido a essas restrições em detrimento pela ideia da "criança comportada" a escola passa a ser a principal responsável por conservar o direito do brincar na educação infantil (SAYÃO, 2002).

Segundo Bento (2017) os diferentes estímulos surgidos no dia a dia e que de certa forma se configuram como potenciais de novas experiências oportunizando novos conhecimentos e competências acontecem com a presença do brincar, uma vez que novos e diferentes desafios estão presentes assumindo papel importante no processo de aprendizagem e desenvolvimento. 
As instituições de ensino deveriam levar em consideração as características das crianças e valorizar o brincar em seus espaços e tempos. O professor precisa ter um olhar pedagógico ao observar as crianças durante a brincadeira aleatória, pois ao brincar a criança estimula várias funções motoras e cognitivas como: personalidade, afetividade, motricidade, inteligência, lateralidade, sociabilidade, criatividade, dentre outras, que se desenvolvem dentro do contexto do livre brincar. "A brincadeira não é um comportamento específico, mas uma situação na qual esse comportamento toma uma significação específica." (BROUGÈRE, 20oI, p.Ioo ).

Atualmente, a tecnologia se faz muito presente na sociedade, contribuindo na diminuição de experiências infantis do brincar ao ar livre e de estarem contato com a natureza. A crescente expansão do mundo digital fascina e mantêm as crianças conectadas às telas contribuindo com o desinteresse delas de frequentar os espaços públicos, que outrora eram utilizados para o brincar. As experiências de brincar na rua ou de ir a pé para a escola passaram a ser substituídas por trajetos de carro até aos locais onde se desenvolvem atividades institucionalizadas, por vezes ficam confinadas a espaços fechados, que limitam os movimentos e as possibilidades de expressão corporal, prejudicando muito o desenvolvimento físico, motor e social das crianças (BENTO, 2017).

O propósito desse trabalho buscou através do estado da arte analisar a produção de conhecimento acerca da importância do "brincar livre" na etapa da educação infantil dentro de instituições escolares. Para atingir este objetivo optamos pela revisão integrativa da literatura, cujo propósito foi o de sistematizar pesquisas já realizadas sobre a contribuição do brincar livre na busca da compreensão da dimensão pedagógica do brincar livre, seus espaços e ampliar as reflexões acerca do papel do professor como mediador nesse processo. 


\section{PROCEDIMENTOS METODOLÓGICOS}

Trata-se de uma revisão de literatura do tipo integrativa, utilizando a base de dados: Scientific Electronic Library Online (SciELO). A pesquisa foi realizada no período de janeiro a dezembro de 2020 e seguiu as fases: busca ou amostragem na literatura, coleta de dados, análise crítica dos estudos incluídos, discussão dos resultados e apresentação da revisão integrativa. Definiu-se como pergunta norteadora: importância do "brincar livre" na etapa da educação infantil dentro de instituições escolares.

Adotou-se uma metodologia que proporciona a síntese do conhecimento e resultados de estudos significativos na prática sobre as evidências científicas sobre o brincar livre no ensino infantil nas instituições escolares. Assim, este estudo investiga e apresenta as evidências científicas que possam direcionar os professores de ensino infantil na prática docente e pedagógica.

Utilizou-se dos seguintes descritores e suas combinações em língua portuguesa: brincar; brincar livre; educação infantil. Os critérios de inclusão definidos para a seleção dos estudos foram os artigos: publicados em português e produzidos no Brasil; indexados dentro do período entre janeiro de 2011 a dezembro de 2020 que retratem a temática do brincar livre na educação infantil, que tenham relação com crianças com idade pré-escolares, pedagogos, educadores, intervenção e olhar pedagógico do brincar.

A partir dos descritores estabelecidos para o estudo, inicialmente foram localizadas 424 referências, que passaram por uma revisão, através das leituras dos resumos resultando após essa etapa na seleção de somente o8 artigos que contemplaram o tema em estudo. A amostra final foi analisada e descrita segundo título, autores, objetivo do estudo, palavras-chave e ano de publicação. Os resultados foram analisados por meio de quatro categorias: o brincar livre na educação infantil, a escola e o brincar, a mediação e o brincar, a criança e o brincar. 


\section{RESULTADOS}

A tabela I apresenta os dados (título, autores, objetivos do estudo, palavraschave e ano de publicação, extraídos dos artigos que resultaram na amostra final da busca nas bases de dados.

Quadro I - Artigos que resultaram na amostra final da busca nas bases de dados $(\mathrm{n}=8)$

\begin{tabular}{|c|c|c|c|c|}
\hline Título do Artigo & Autores & Objetivo(s) de estudo & Palavras Chaves & Ano \\
\hline $\begin{array}{l}\text { Em cada lugar um } \\
\text { brincar: reflexão } \\
\text { evolucionista sobre a } \\
\text { universalidade e } \\
\text { diversidade }\end{array}$ & $\begin{array}{l}\text { Reginalice de } \\
\text { Lima Marques e } \\
\text { Ilka Dias Bichara. }\end{array}$ & $\begin{array}{l}\text { Buscar evidências apontadas por pesquisas mostrando } \\
\text { particularidades observadas nas brincadeiras em } \\
\text { contextos específicos e refletir a partir da abordagem } \\
\text { evolucionista, relacionando características intrínsecas } \\
\text { das brincadeiras com possíveis funções e adaptações } \\
\text { filogenéticas e ontogenéticas, na espécie humana. }\end{array}$ & $\begin{array}{l}\text { Brincadeira } \\
\text { Infantil. } \\
\text { Diversidade. } \\
\text { Perspectiva. } \\
\text { Evolucionista. }\end{array}$ & 2011 \\
\hline $\begin{array}{l}\text { Brincar e mediação } \\
\text { na escola }\end{array}$ & $\begin{array}{l}\text { Mariana } \\
\text { Stoeterau } \\
\text { Navarro e Elaine } \\
\text { Prodócimo. }\end{array}$ & $\begin{array}{l}\text { Refletir sobre a mediação do brincar na escola: como as } \\
\text { diferentes formas de mediação do professor têm } \\
\text { influência na qualidade do brincar das crianças. }\end{array}$ & $\begin{array}{l}\text { Brincar. } \\
\text { Mediação. } \\
\text { Educação Infantil. } \\
\text { Escola. }\end{array}$ & 2012 \\
\hline $\begin{array}{l}\text { A escola de educação } \\
\text { infantil na } \\
\text { perspectiva das } \\
\text { crianças }\end{array}$ & $\begin{array}{l}\text { Fernanda } \\
\text { Martins Marques } \\
\text { e Tânia Mara } \\
\text { Sperb. }\end{array}$ & $\begin{array}{l}\text { Compreender as concepções das crianças acerca da escola } \\
\text { de educação infantil, com estudo baseado na perspectiva } \\
\text { histórico-cultural através da análise do contexto do } \\
\text { brincar. }\end{array}$ & $\begin{array}{l}\text { Concepções de } \\
\text { Crianças. } \\
\text { Educação Infantil. } \\
\text { Brincar. } \\
\text { Desenvolvimento } \\
\text { Infantil. }\end{array}$ & 2013 \\
\hline $\begin{array}{l}\text { A criança e a } \\
\text { infância sob o olhar } \\
\text { da professora de } \\
\text { educação infantil }\end{array}$ & $\begin{array}{l}\text { Carla Tosatto e } \\
\text { Evelise Maria } \\
\text { Labatut Portilho. }\end{array}$ & $\begin{array}{l}\text { Construir unidades de significação do que é ser criança: } \\
\text { um ser naturalmente bom; um ser que vive na fantasia; } \\
\text { um ser que brinca, que aprende e se desenvolve. }\end{array}$ & $\begin{array}{l}\text { Educação Infantil. } \\
\text { Unidades de } \\
\text { Significação. } \\
\text { Formação } \\
\text { Continuada. }\end{array}$ & 2014 \\
\hline $\begin{array}{l}\text { O brincar nos } \\
\text { discursos de } \\
\text { estudantes de } \\
\text { pedagogia: certezas } \\
\text { em suspenso. }\end{array}$ & $\begin{array}{l}\text { Circe Mara } \\
\text { Marques; Susana } \\
\text { Beatriz } \\
\text { Fernandes e } \\
\text { Ezequiel } \\
\text { Theodoro da } \\
\text { Silva. }\end{array}$ & $\begin{array}{l}\text { Analisar um conjunto de discursos sobre o brincar, } \\
\text { produzidos por estudantes de pedagogia de uma } \\
\text { universidade no Sul do Brasil. }\end{array}$ & $\begin{array}{l}\text { Brincar. Discurso. } \\
\text { Educação Infantil. } \\
\text { Pedagogia. }\end{array}$ & 2016 \\
\hline $\begin{array}{l}\text { Avaliação do brincar } \\
\text { de faz de conta de } \\
\text { pré-escolares: revisão } \\
\text { integrativa de } \\
\text { literatura }\end{array}$ & $\begin{array}{l}\text { Renata Valdívia } \\
\text { Lucisano, Letícia } \\
\text { de Carli Novaes, } \\
\text { Amanda Mota } \\
\text { Pacciulio Sposito, } \\
\text { Luzia Iara } \\
\text { Pfeifer. }\end{array}$ & $\begin{array}{l}\text { Identificar estudos sobre o brincar simbólico/faz de } \\
\text { conta de pré-escolares tem sido avaliado, quais os } \\
\text { objetivos destes estudos e quais instrumentos têm sido } \\
\text { utilizados para avalizar esse comportamento. }\end{array}$ & $\begin{array}{l}\text { Educação } \\
\text { Especial. Criança } \\
\text { Pré-Escolar. Faz } \\
\text { de Conta. } \\
\text { Instrumentos de } \\
\text { Avaliação. }\end{array}$ & 2017 \\
\hline
\end{tabular}




\begin{tabular}{|c|c|c|c|c|}
\hline $\begin{array}{l}\text { Narrativas sobre o } \\
\text { brincar: aproximação } \\
\text { da experiência } \\
\text { infantil }\end{array}$ & $\begin{array}{l}\text { Cássio Vinícius } \\
\text { Afonso Viana, } \\
\text { Jaquelina Maria } \\
\text { Imbrizi e Andrea } \\
\text { Perosa Saigh } \\
\text { Jurdi. }\end{array}$ & $\begin{array}{l}\text { Relatar a experiência do projeto de iniciação científica, } \\
\text { cuja pesquisa com viés qualitativo se fez por meio de } \\
\text { observação participante, produção de diários de campo, } \\
\text { elaboração e análise de duas narrativas sobre o brincar } \\
\text { com crianças. }\end{array}$ & $\begin{array}{l}\text { Infância. } \\
\text { Narrativas. } \\
\text { Brincar. }\end{array}$ & 2017 \\
\hline $\begin{array}{l}\text { O brincar e o } \\
\text { cuidado nos } \\
\text { espaços da educação } \\
\text { infantil: } \\
\text { desenvolvendo os } \\
\text { animais que somos }\end{array}$ & $\begin{array}{l}\text { Rodrigo Avila } \\
\text { Colla. }\end{array}$ & $\begin{array}{l}\text { Discutir o brincar e o cuidado como tarefas constitutivas } \\
\text { do desenvolvimento humano. }\end{array}$ & $\begin{array}{l}\text { Animalidade. } \\
\text { Brincar. Cuidado. } \\
\text { Educação Infantil. } \\
\text { Espaço Escolar. }\end{array}$ & 2019 \\
\hline
\end{tabular}

\section{DISCUSSÃO}

O tema "brincar livre" foi discutido nos artigos dos seguintes autores: NAVARRO e PRODÓCIMO (2012); COLLA (2019), MARQUES e BICHARA (20II) e VIANA, IMBRIZI, JURDI (20I7). Os estudos de LUCISANO, NOVAES, SPOSITO e PFEIFER (2017); e MARQUES e SPERB (2013) discutem o tema dentro da perspectiva da brincadeira de faz-de-conta. TOSATTO e PORTILHO (2014) trabalham a questão do olhar pedagógico da professora de educação infantil afim de construir unidades de significação do que realmente é ser criança. MARQUES e FERNANDES (2019) discutem o brincar sob o discurso das estudantes de pedagogia de uma universidade do sul do Brasil.

Podemos afirmar que os textos chegam a um consenso sobre a importância do brincar da criança nos primeiros anos de vida e que vários fatores relacionados ao brincar influenciam no desenvolvimento infantil. $O$ brincar é uma atividade dinâmica e subjetiva, uma ferramenta para a aprendizagem em contexto sociocultural que acontece naturalmente, em um processo de relações interindividuais que se deve levar em consideração os diferentes sujeitos envolvidos, as diferentes gerações e os fatores externos (social e cultural).

O brinquedo tem um importante papel na mudança da relação entre o campo da percepção visual e o campo do significado. O comportamento infantil passa ser dirigido pelo que determinada ação significa para a criança, e não apenas pela percepção imediata dos objetos. (NAVARRO; PRODÓCIMO, 2012) 
Os artigos abordam sobre o ambiente escolar que deve ser adaptado e construído para as crianças, as salas de aula precisam estar organizadas com recursos metodológicos à disposição de todos, a importância das instituições escolares de educação infantil em discutir a questão do brincar e do cuidado como tarefas constitutivas do desenvolvimento humano; a disponibilização de materiais pedagógicos adequados; as práticas de ensino-aprendizagem e os pedagogos precisam estar atentos a potências que estimulam a livre iniciativa das crianças que propiciem suas descobertas de modo lúdico. O cuidar traz a idéia de preservação da vida, de atenção, de acolhimento, envolvendo uma relação afetiva e de proteção. (SALLES; FARIA, 2007)

Já sobre a importância da atuação do professor como mediador, ele representa o elemento intermediário e uma ferramenta auxiliar da atividade humana. A intervenção pedagógica provoca avanços que não ocorreriam espontaneamente, destaca interações cotidianas pela intencionalidade da ação.

$\mathrm{Na}$ escola, relação entre os adultos e crianças é de ensino, é uma relação explícita, onde a criança entende qual o papel do professor e o que é esperado dela neste contexto. A mediação tem relevância para que a criança brinque com qualidade, podendo contribuir como: uma perspectiva histórico cultural; um pressuposto norteador e seu arcabouço teórico-metodológico. (NAVARRO; PRODÓCIMO, 2012).

Para as crianças a brincadeira é importante por ela mesma e uma experiência de autoprodução. A criança é como um ser que vive na fantasia, um ser que brinca, aprende, desenvolve e o brincar é um processo de ensino-aprendizagem com a presença da ludicidade principalmente ao tratar de pequenos aprendizes.

As crianças não são passivas frente as suas experiências na escola e podem contribuir para o desenvolvimento dessas instituições, se escutadas. É importante ouvir as crianças, o brincar sempre esteve presente em todas as falas delas na educação infantil, críticas delas dirigidas às instituições falam sobre a falta de espaço, 
de tempo e de objetos para brincar (MARQUES; SPERB, 2013). Favorecer a possibilidade de reflexão acerca da criança e da infância, a fim de provocar novos olhares, novas interações e novas ações, possibilita a criança compreender melhor o mundo que a cerca.

\section{O BRINCAR LIVRE NA EDUCAÇÃO INFANTIL}

O que é o livre brincar ou brincar livre? É uma forma de dar liberdade e oferecer novas experiências às crianças, deixando com que brinquem livremente, utilizando sua criatividade, imaginação e que busquem por novos desafios sem a mediação da professora (PENINA, 2016). Deixar a criança confiar em si mesma e sentir-se capaz de realizar coisas que nem ela mesma imaginava que conseguiria fazer. O aumento de veículos, a violência e o avanço da tecnologia tomam conta do espaço das crianças, a liberdade de estar em contato com a natureza, de poder brincar no parquinho e sentir o ar livre.

O brincar livre por sua vez, é uma "apropriação ativa do real por meio da representação" (FORTUNA, 2014, p. 24, apud COLLA, 2019, p. II3). Quando a criança brinca, ela se prepara de forma inconsciente para o mundo adulto, pois a brincadeira possibilita o acesso a novas descobertas, contribuindo na aquisição do conhecimento e da socialização. A proposta pedagógica lúdica, em que o brincar é visto como uma forma privilegiada de instigar a aquisição da função simbólica, possibilita às crianças compreender o mundo e se expressar através da linguagem plástica e visual. (SALLES; FARIA, 2007)

O brincar pode ser a base fundamental para discutir vários aspectos acerca da brincadeira, já que se trata de um fenômeno diretamente relacionado ao desenvolvimento humano. Para entender melhor seu papel no desenvolvimento e na sua funcionalidade, a brincadeira tem sido objeto de pesquisas que buscam descrever o brincar em culturas e contextos específicos, associado ou não com aspectos do desenvolvimento infantil. (MARQUES; BICHARA, 2oII). 
Tais estudos ajudam a pensar sobre como as formas variadas de brincar podem demonstrar sua funcionalidade adaptativa na infância. Morais e Otta (2003) concordam que a atribuição das diversas formas de brincar à pouca quantidade de brinquedos estruturados oferecidos acaba contribuindo com a imaginação das crianças. Segundo as autoras, o grande espaço livre disponível para brincar, hábitos de brincadeiras fora da escola e a atitude dos pais em relação ao brincar constituem fatores que podem influenciar a maneira como as crianças brincam. Neste aspecto, cria-se um conceito chamado de "zona lúdica", que representa o espaço no qual ocorre o brincar (MORAIS e OTTA, 2003)

O conceito de "zona lúdica" (o espaço onde ocorre o brincar) define fatores, isolados ou em conjunto, que influencia a maneira como as crianças brincam e implica na consideração da qualidade dos contextos particulares que refletem e indicam evidências de que o brincar figura como um comportamento próprio do período de infância, onde a criança adquiri, cria e transmite a cultura (MARQUES; BICHARA, 2OII).

Em relação às condições ambientais e de recursos disponíveis, indiferente ao conceito adulto, a criança que brinca apropria-se do espaço e constrói seus próprios significados sobre ele, interagindo ativamente e adaptando as brincadeiras, determinando papéis, regras e o uso de variados objetos, entre outras possibilidades (MARQUES; BICHARA, 20II).

Para estudar sobre o brincar, é necessário, ser e ouvir as crianças. A escassez de espaços públicos vem sendo consumada com o aumento cada vez mais frequente dos espaços privados, bem como nas casas e em instituições como a escola apontam a precariedade das experiências do livre circular e brincar da infância no mundo contemporâneo, configurando para o ideal capitalista de produção, na qual a posse de brinquedos e de equipamentos tecnológicos ganham prioridade frente às brincadeiras de roda, de rua, de expressão corporal. 
O brincar é uma ferramenta de importância subjetiva, identitária e social, e também um modo de produção de saber na infância (VIANA; IMBRIZI; JURDI, 2017). Em pleno século XXI as crianças estão tomando para si responsabilidades e ingressando de forma precoce ao mundo adulto de forma inconsciente. Isoladas de outras crianças, os espaços temporais tornam-se cada vez menores para produzir com o coletivo os sentidos da infância e de ser criança no mundo. Brincar é uma das múltiplas linguagens das crianças, linguagens essas que vão se apropriando e se constituindo pelos aspectos sócio culturais.

\section{A ESCOLA E O BRINCAR}

A brincadeira é uma atividade fundamental na educação infantil. Quando o tema discutido é o brincar na escola, deve-se pensar como item de grande importância dentro do contexto escolar, onde a mediação do educador possibilite a criança brincar com qualidade.

Uma brincadeira precisa ser interessante, precisa chamar a atenção das crianças o tempo inteiro e ao mesmo tempo gerar um ambiente de aprendizagem bem agradável aos olhos delas. Muitas vezes, pela importância de ser livre, o brincar na escola acaba não sendo planejado e não tendo uma atenção especial das professoras, como se bastasse deixar brincar, como se fosse uma atividade apenas natural, e não social e cultural (BROUGÈRE, 200I).

Para Tosatto e Portilho (2014) o brincar precisa ser mais explorado pelas crianças no espaço escolar, ou seja, cabe ao professor dentro do seu planejamento oportunizar e desenvolver atividades que contemplem o brincar e mesmo num brincar livre que seja organizado e com intencionalidade pedagógica.

É possível incluir o brincar planejado no cotidiano da escola, sem que seja posto e engessado pelo adulto, em que as crianças tenham o direito de escolher e opinar sobre a brincadeira, e possam modificá-la ou criar novas formas de brincá-la. 
A escola precisa ter uma estrutura física agradável, compatíveis e que atendem as necessidades das crianças, como a utilização de materiais escolares, brinquedos e recursos tecnológicos disponibilizados pela instituição. Sabe-se da importância da intencionalidade nas ações educativas e que o uso do brincar na escola deve estar revestido de intenções e significados construídos pelas professoras, os quais são orientadores do planejar e do participar do brincar das crianças na escola (MARQUES; SPERB, 2013).

Apesar que a maioria dos educadores saibam sobre a importância do brincar na educação infantil, esse conhecimento nem sempre se reflete no cotidiano das escolas. As rotinas escolares ainda enfatizam o cuidado ou o caráter escolarizante nas atividades desenvolvidas por instituições pré-escolares, onde a imposição da disciplina, de regras, proibições e as tentativas de controle do comportamento das crianças prevalecem de forma rigorosa. Outro fator observado são os espaços escolares que não oferecem dispositivos para o estímulo da criatividade e imaginação das crianças.

De acordo com Fortuna (2014) o brincar na escola são separados das atividades escolares e as práticas pedagógicas acabam por não contemplar momentos de brinquedos e de brincar na escola, com raras exceções e momentos, como ter o cantinho dos brinquedos ou o dia do brinquedo, isso ainda se configurando apenas no ensino infantil, o que no ensino fundamental essas alternativas são abominadas, não contemplando as demais tarefas escolares

Portanto, as instituições escolares deveriam repensar sobre o brincar, no seu aspecto didático metodológico, nas estruturas, materiais e espaços físicos, oportunizando e oferecendo para as crianças entrarem em contato com a natureza, espaços externos, playgrounds, hortas, flores e árvores onde possam brincar, investindo em brincadeiras com diversos tipos de brinquedos, oferecer materiais recicláveis onde as crianças possam usar a criatividade, adequar os horários de atividades, usar a tecnologia somente para meios de aprendizagem através do brincar, 
explorar mais esses espaços, deixando as crianças fluírem a imaginação e o faz de conta para contribuir para uma aprendizagem mais significativa.

\section{A MEDIAÇÃO E O BRINCAR}

Atualmente, alguns professores deixam a desejar na questão do brincar livre, tornando esta ferramenta de grande importância para a educação infantil incompatível com as preocupações relacionadas ao ensino e aprendizagem.

$\mathrm{O}$ adulto deve intervir apenas para garantir o bem-estar das crianças e saber observar os processos de exploração a partir delas mesmas. A brincadeira como um potencial educativo tende a nos levar a priorização dos aspectos de desenvolvimento culturais e humanos (FOLCHI, 2015; COLLA, 2019).

As crianças jamais devem ficar de forma alheia brincando e realizar outras tarefas, o olhar pedagógico deve estar concentrado o tempo inteiro e estar atento às informações que estão sendo geradas naquele momento dentro da atividade proposta. Dar liberdade às crianças não significa a completa omissão do docente, o brincar deve ser interpretado como formas de linguagens, que são expressas inconscientemente pelas crianças, cabendo aos educadores compreenderem $o$ que as mesmas transmitem, pois é uma das maneiras de conseguir conhecê-las melhor (FORTUNA, 2014).

O brincar deve ser uma atividade dinâmica onde as crianças têm a liberdade na escolha das brincadeiras, trabalhando assim o desenvolvimento sociocultural do sujeito em si, assimilando o tempo cronológico dando importância ao intrínseco das mesmas (BROUGÈRE, 200I).

$\mathrm{Na}$ escola, a atuação do professor como mediador remete a ideia do pressuposto vygotskiano, onde a relação do homem com o mundo não é direta e sim mediada: uma "ferramenta auxiliar da atividade humana" (OLIVEIRA, 1993).

A intervenção pedagógica não ocorreria espontaneamente, a intervenção deliberada de um indivíduo sobre outros, articula-se como um postulado básico onde 
a aprendizagem é fundamental desde o nascimento da criança. O importante para a criança é o brincar e não qual aprendizado esta atividade trará. Ao dar ideias, sugestões e organizando o ambiente, a professora propõe uma situação estimuladora e partindo desse processo em resposta a criança, cria-se uma estrutura produtora de comportamento definido como medição (VIGOTSKY, I99I).

A rotina da Educação Infantil revela-se nas práticas pedagógicas, nas interações e experiências sociais que se manifestam e silenciam as crianças. $O$ papel do educador na mediação e organização do tempo/espaço ao ministrar as atividades pedagógicas relacionadas à arte do brincar, deve referenciar o desenvolvimento da criança em diferentes contextos de mediação dentro ou fora da sala de aula (VYGOTSKY, 2010).

As crianças devem ter à disposição uma variedade de objetos de qualidade e adequados para o brincar. Os educadores devem ter a consciência sobre a importância de apresentar diversas formas de brincadeiras (tradicionais e atuais) e estar disposto em aprender com as crianças, interagindo com suas brincadeiras preferidas. (SMITH, 2006).

Assim, o professor precisa valorizar a arte do brincar como uma ferramenta poderosa no processo de ensino e aprendizagem na Educação Infantil. Por meio das brincadeiras pode-se conhecer melhor o íntimo de cada criança envolvida. O olhar crítico e pedagógico necessita estar direcionada constantemente sobre as crianças. Com esse olhar é possível descobrir as dificuldades de aprendizagem, se a criança é sociável ou não, se interage bem com outras crianças e os problemas que possa estar acontecendo.

\section{A CRIANÇA E O BRINCAR}

No brincar, a criança é (ou deveria ser) protagonista de sua ação. O brincar não se configura num espaço de produção cultural, de autoria, de invenção e diálogo com o mundo, mas, sim, de controle, de "ensino", onde predomina a instrução do 
professor e não as linguagens e produções simbólicas das crianças. Viana, Imbrizi e Jurdi (2017) destacam que as crianças foram pensadas prioritariamente como objetos ou destinatários de processos de socialização, pelos quais as gerações mais novas adquirem normas, valores, crenças e ideias do seu grupo social a qual pertencem, sendo introduzidas à reprodução social.

Isso se manifesta na prática desenvolvida na escola, pois, em geral, a criança ocupa um lugar mais passivo, que ativo; mais de reprodução do que de criação; mais de espera do que de iniciativa; mais de ouvir, do que de ser ouvida.

Em um projeto pedagógico realizado em uma escola pública de educação infantil, Marques e Sperb (2013) afirmam que são poucos os estudos relacionados às falas das crianças da educação infantil e diz que os alunos não deveriam ser considerados como indivíduos passivos frente a suas experiências na escola, pois poderiam contribuir para o desenvolvimento dessas instituições, se fossem mais ouvidos.

Foi por meio da metodologia do brincar de faz-de-conta, que os pesquisadores através do olhar pedagógico, conseguiram apurar os resultados em temáticas relacionadas ao que as crianças pensam sobre: o brincar, a atividades de ensinoaprendizagem, espaço físico, professores, regras, função da escola, as relações com outras crianças e gênero.

Os estudos revelam que o brincar está presente em todas as falas das crianças, em suas críticas, elas se queixam da falta de tempo, de espaço e de objetos para brincar. A brincadeira de faz-de-conta é a brincadeira favorita no contexto da escola de educação infantil. As crianças, quando escutadas em pesquisas, mencionam com frequência as regras e disciplina da escola; essas características fazem com que o desenvolvimento das crianças fica em segundo plano. Embora o brincar seja, atualmente, reconhecido como um lugar "ecologicamente relevante" para o estudo do desenvolvimento infantil, ainda são poucas as pesquisas que usam esse contexto ao investigar as concepções das crianças sobre a escola. (MARQUES, SPERB, 2013) 
Durante o brincar pode-se perceber a diversidade de fenômenos que apresentam as particularidades observadas nas brincadeiras infantis em contextos específicos. Se dermos voz às crianças que estão nas casas, ruas, instituições, buscando a construção de sua própria história e de seus espaços para o brincar, seja possível que elas nos relatem situações que envolvam sentimentos e sensações diferentes da expectativa de alguns adultos e que, portanto, sejam disparadores para a construção de novos caminhos, de outros olhares e de uma pluralidade de experiências que se disponham ao encontro e à produção de novas infâncias (GALIANI, 2013).

Ao brincar a criança diz um pouco do que é e como é ser criança através de suas experiências, o brincar é mais que uma experiência de troca, é uma experiência criadora, uma forma básica de viver, é como uma atitude que diz mais do que a fantasia, que conta a realidade de maneira infantil, como as crianças a percebem e como elas encaram esses processos culturais de existência e significação social (WINNICOT, 1975 APUD VIANA, IMBRIZI, JURDI, 2017).

\section{CONSIDERAÇÕES FINAIS}

O presente estudo teve como objetivo sistematizar a contribuição do brincar livre na busca da compreensão da dimensão pedagógica dessa temática, seus espaços e ampliar as reflexões acerca do papel das instituições e do professor como mediador no processo de ensino e aprendizagem no contexto da educação infantil e suas relações.

Podemos conceber que tais informações nos suscitaram acerca das lacunas, contradições e paradigmas diante dos resultados encontrados de modo a produzir novos conhecimentos, uma vez que o número de publicações ainda se mostra de maneira tímida, incipiente, o que nos certifica que estamos no caminho, no qual temos muito a investigar, estudar e descobrir sobre este tema tão relevante. 
As produções analisadas revelaram construções teóricas, vivências, relatos e experiências mostrados em contextos diferentes sobre o brincar, o brincar livre, o educador e a instituição escolar, demonstrando que muitos deles se mantêm distantes em relação teoria e a prática, ou seja, da ação pedagógica voltada para esse tema.

Debater e discutir concepções e ações que remetem à docência, instituição de ensino, aspectos didáticos metodológicos é indispensável para possibilitar mudanças de posturas, rupturas, construção de conhecimento e diálogo na busca de melhorias e aperfeiçoamento para a educação infantil.

Diante disso, notamos que temos um longo caminho a percorrer na busca incessante de investigar os diversos aspectos que são peculiares do brincar livre na infância, na docência e na educação infantil por ora apresentados.

\section{REFERÊNCIAS BIBLIOGRÁFICAS}

ALVES, L.; BIANCHIN, M. A. O jogo como recurso de aprendizagem. Revista Psicopedagogia, São Paulo. V.27, n83, p. 282-287, 2010.

ARIÈS, Philippe. História social da criança e da família. Trad. Dora Flaksman. $2^{\underline{a}}$ edição. Rio de Janeiro: Editora Guanabara, 1981. p.279

BARBOSA, Hamilton B. A construção histórica do sentimento de infância: (da idade média à moderna). Educadores dia a dia. Ano 2007. Universidade Salgado de Oliveira. Curso de História. Disponível em: < http://www.educadores.diaadia.pr.gov.br/arquivos/File/2010/artigos_teses/2010/Hi storia/monografia/monocrianca.pdf > Acesso em: 12/02/2021.

BENTO, Maria Gabriela Portugal. Arriscar ao brincar: análise das percepções de risco em relação ao brincar num grupo de educadoras de infância. Rev. Bras. de Educação, abr-jun. 2017, vol. 22, no. 69, p.385-403.

BISPO, J.G.; DOURADO, R. N. S.; DOURADO, E. O. C. O brincar livre numa creche pública no município de Irecê (BA): concepções em foco. Revista Humanidades e Inovação, v.6, n.15, p. 326-336, 2019. 
BROUGÈRE, G. Brinquedo e cultura. 4. ed. São Paulo: Cortez, 200 I.

COLLA, R. A. O brincar e o cuidado nos espaços da educação infantil:

desenvolvendo os animais que somos. Rev. Bras. Estud. Pedagog., Abr 2019, vol.roo, no.254, p.III-I26. ISSN 2176-668I.

FOCHI, P. Afinal, o que os bebês fazem no berçário? Porto Alegre: Penso, 2015.

FORTUNA, T. R. A importância de brincar na infância. In: HORN, C. I. et al.

Pedagogia do brincar. Porto Alegre: Mediação, 2014.

GARIÉPY, N.; HOWE, N. The therapeutic power of play: examining the play of young children whith leukaemia. Child: Care, Health and Development, V.29, n.6, p. $523-537,2003$.

LUCISANO, R. V.; NOVAES, L. C.; SPOSITO, A. M. P.; PFEIFER, L.

I. Avaliação do Brincar de Faz de Conta de Pré-Escolares: Revisão Integrativa da Literatura. Rev. bras. educ. espec., Jun 2017, vol.23, no.2, p.309-322. ISSN I413-6538 MARQUES, C. M.; FERNANDES, S. B.; Silva, E. T. da. O brincar nos discursos de estudantes de Pedagogia: certezas em suspenso. Proposições, 2019, vol.30. ISSN ого7307

MARQUES, R. de L.; BICHARA, I. D. Em cada lugar um brincar: reflexão evolucionista sobre universalidade e diversidade. Estud. psicol. (Campinas), Set 2oII, vol.28, no.3, p.38I-388. ISSN ого-г66X.

MARQUES, F. M.; SPERB, T. M. A escola de educação infantil na perspectiva das crianças. Psicol. Reflex. Crit. [online]. 2013, vol.26, n.2, pp.4I4-421. ISSN oı02-7972. MENDES, K. D. S.; SILVEIRA, R. C. de C. P. e GALVÃO, C. M. Revisão integrativa: método de pesquisa para incorporação de evidências na saúde e na enfermagem. Texto Contexto Enferm., Florianópolis, SC. V.17, n.4, p.758-764, 2008. MORAES, M. S.; OTTA, E. Entre a serra e o mar. In A. M. A. Carvalho, C. M. C. Magalhães, F. A. R. Pontes \& I. D. Bichara (Orgs.). Brincadeira e cultura: viajando pelo Brasil que brinca (pp.127-156). São Paulo: Casa do Psicólogo, 2003. 
NAVARRO, M. S.; PRODÓCIMO, E. Brincar e mediação na escola. Rev.

Bras. Ciênc. Esporte, Set 2or2, vol.34, no.3, p.633-648. ISSN oior-3289.

OLIVEIRA, M. K. Vigotsky: aprendizado e desenvolvimento um processo sóciohistórico. São Paulo: Scipione, 1993. Disponível: <

https://www.passeidireto.com/arquivo/68405126/vygotsky-aprendizado-edesenvolvimento-um-processo-socio-historico-marta-kohl-ol> Acesso em: 23/02/2021. PENINA, M. O que significa proporcionar o brincar livre? Catraca Livre, 2016. Disponível em: < https://catracalivre.com.br/catraquinha/o-que-significaproporcionar-o-brincar-livre-2/ > Acesso em: 13/02/2021.

SALLES, F.; FARIA, V. O currículo na educação infantil: as relações da criança com os saberes e conhecimentos da natureza e cultura. Educadores dia a dia, 2007.

Disponível em:<

http://www.educadores.diaadia.pr.gov.br/arquivos/File/pdf/curriculo.pdf>Acesso em: $15 / 02 / 2021$.

SAYÃO, D. T. Corpo e movimento: notas para problematizar algumas questões relacionadas à educação infantil e à educação física. Revista Brasileira de Ciências do Esporte, Campinas, v.23, n. 2, p. 55-67, jan. 2002.

SMITH, P. K. (2006). O brincar e os usos do brincar. In J. R. Moyles et al., A excelência do brincar (M. A. V. Veronese, Trad., pp.25-38). Porto Alegre: Artmed. Disponível em: $<$ https://staticsshoptime.b2w.io/sherlock/books/firstChapter/5912753.pdf > Acesso em 20/02/2021. TOSATTO, C.; PORTILHO, E. M. L. A Criança e a infância sob o olhar da professora de educação infantil. Educ. rev., Set 2014, vol.30, no.3, p.153-172. ISSN oio24698.

VIANA, C. V. A.; IMBRIZI, J. M.; JURDI, A. P. S. Narrativas sobre o brincar: aproximação da experiência infantil. Psicol. Soc., 2017, vol.29. ISSN o102-7182. 
VIGOTSKY, L. S. Aprendizagem e desenvolvimento intelectual na idade escolar.

In: LURIA, A. R.; LEONTIEV, A. N. Linguagem, desenvolvimento e aprendizagem. II. ed. São Paulo: Ícone, 20ı0. p.ıoz-II7.

VIGOTSKY, L. S. A Formação social da mente. 4. ed. São Paulo: Martins Fontes, I991. 